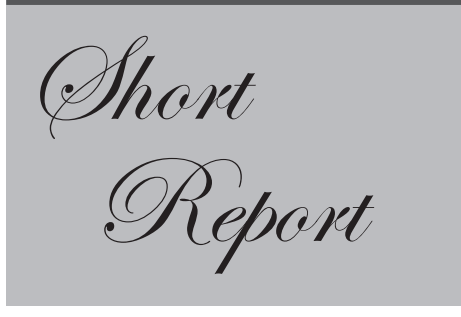

\title{
The Conundrum of Histology in Crohn's Disease
}

\author{
Mayank Jain, M Srinivas, Mahadevan B, Ravi R, \\ Jayanthi Venkataraman
}

Department of Medical Gastroenterology,

Gleneagles Global Health City, Chennai

Corresponding Author: Dr Mayank Jain

Email:mayank4670@rediffmail.com

The enigma of diagnosing Crohn's disease (CD) has puzzled clinicians for several decades. Clinical, colonoscopic, radiological and histological criteria are used as complementary tests to diagnose ileocolonic CD. ${ }^{1,2}$ In clinical practice, it is not uncommon to perceive that these four major diagnostic modalities yield inconclusive and, quite often, opposing results.Majority of the Indian studies have highlighted the dilemma of distinguishing CD from tuberculosis (TB). ${ }^{3-5}$ Amarapurkar et al reported that the accuracy of predicting CD was $84 \%$ based on symptoms while it was $63 \%$ when histology was reported as inflammatory bowel disease and $42 \%$ if there was recurrence of disease after surgery. ${ }^{6}$ The criteria designed by Pulimood et $\mathrm{al}^{7}$ are currently used to distinguish $\mathrm{CD}$ from intestinal TB. We attempted to corroborate the histological description of ileocolonic CD using Pulimood's classification for $\mathrm{CD}$, considering the response to treatment with steroids and/or immunosuppressants as the gold standard.

\section{Methodology}

This retrospective study was done at the Department of Medical Gastroenterology, Gleneagles Global Health City, Chennai. It included 42 patients of ileocolonic CD who had responded to treatment. Patient information including history, clinical examination and findings at colonoscopy were noted. Multiple tissue specimens were taken from both the diseased and normal appearing mucosa, the latter at $10 \mathrm{~cm}$ intervals from ileum to rectum. ${ }^{8}$ Response to treatment i.e. clinical response and/or repeat colonoscopy showing healing of lesions was considered as gold standard for diagnosis of CD.

Inclusion criteria for clinical presentation included patients presenting with clinical symptoms of inflammatory bowel disease (abdominal pain, chronic mucoid diarrhoea with or without blood, weight loss, malabsorption, CT or MR enterography favouring $\mathrm{CD}$ and who responded to treatment with steroids/ immunosupressants. Colonoscopic inclusion criteria were presence of two or more lesions such as perianal lesions, aphthous ulcers, fissuring ulcers, skip lesions, long segment stricture, cobblestone appearance orileal involvement with preservation of the IC valve.

\section{The histological appearance was classifiedas:}

Histological CD-Typical granuloma $<400 \mu \mathrm{m}$ in maximum dimension, less than four sites of granulomatous inflammation per site, no caseation, and location of granulomas in rectosigmoid;Focally enhanced colitis; Pericryptal granulomatous inflammation and architectural alteration / activity / chronic inflammation / deep ulceration at sites that do not show granulomatous 
response in the same or adjacent segments. ${ }^{7}$

Acute ileitis (presence of 4 or more features)Presence of mucosal aphthous ulcers with scattered eosinophils, neutrophil infiltration and alternate bands of fibrosis in the lamina propria extending up to the mucosal surface; large reactive lymphoid follicles; follicle-centric nonnecrotizing epithelioid cell granulomas. ${ }^{9}$

Chronic ileitis without granulomas (presence of 4 or more features)-distortion of the mucosal crypt architecture, predominance of lymphomononuclear cells, plasma cells, eosinophils, pyloric metaplasia, goblet cell rich crypts (hypercrinia), mucosal basal plasmacytosis, broadening of the ilealvillous, crypt branching, crypt shortening and the crypt loss. ${ }^{9}$

Non specific inflammation/ileitis-ileal inflammation with none of the above features. ${ }^{9}$

\section{Results}

The study included 42 patients ( 26 females, $62 \%$ ) whose mean age $( \pm \mathrm{SD})$ was $27( \pm 5.2)$ years. All the 42 patients responded to treatment (steroids/azathioprine) and had been on a median followup of 13 months (range 6-22 months). Classical histopathological features of $\mathrm{CD}$ were noted in 25 cases $(59.5 \%)$. In the remaining (17) cases, 10 (59\%) had chronic ileitis without granulomas, 5 (29.4\%) had acute ileitis and $2(11.6 \%)$ had nonspecific inflammation.

\section{Discussion}

Thus, classical / pathognomic histological features of $\mathrm{CD}$ were present in $60 \%$ of the cases. In the remaining, clinical and colonoscopy features suggestive of $\mathrm{CD}$, with regular follow up to assess response dictated management of these patients with steroids \pm azathioprine.

Our study highlights the continuing relevance of clinical presentation and colonoscopy findings for treatment initiation and monitoring, in the absence of classical histological findings in ileocaecal CD in as many as two-fifths of the patients. Research into advanced pathological studies like immunohistochemistry may help to fill the current gap in definitive $\mathrm{CD}$ diagnosis from biopsy specimens.

\section{References}

1. Dutta AK, Sahu MK, Gangadharan SK, et al.Distinguishing Crohn'sdisease from intestinal tuberculosis - a prospective study.TropicalGastroenterol 2011;32(3):204-9

2. Prabhu PR, Jain M, Bawane P, et al. Role of colonoscopy in differentiating intestinal tuberculosis from Crohn's disease. J Dig Endosc 2017;8:72-7

3. Makharia GK, Srivastava S, Das P, et al. Clinical, endoscopic, and histological differentiations between Crohn's disease and intestinal tuberculosis. Am J Gastroenterol. 2010 ;105(3):642-51

4. Das K, Ghoshal UC, Dhali GK, et al. Crohn's disease in India: a multicenter study from a country where tuberculosis is endemic. Dig Dis Sci. 2009 ;54(5):1099-107.

5. Jayanthi V, Robinson RJ, Malathi S et al. Does Crohn's disease need differentiation from tuberculosis? J GastroenterolHepatol 1996; 11: 183-6

6. Amarapurkar DN, Patel ND, Rane PS. Diagnosis of Crohn's disease in India where tuberculosis is widely prevalent. World JGastroenterol 2008; 14(5): 741-6

7. Pulimood AB, Ramakrishna BS, Kurian G, et al. Endoscopic mucosal biopsies are useful in distinguishing granulomatous colitis due to Crohn's disease from tuberculosis. Gut 1999; 45: 537-41

8. Pulimood AB, Peter S, Ramakrishna B, et al. Segmental colonoscopic biopsies in the differentiation of ileocolic tuberculosis from Crohn's disease. J GastroenterolHepatol 2005;20:688-96

9. Das P, Gahlot GP, Mehta R, Gupta SD.Interpretation of ileal biopsies. Indian J PatholMicrobiol2015;58:146-5. 